\title{
The Role of Chelating Diamine Ligands in the Goldberg Reaction: A Kinetic Study on the Copper-Catalyzed Amidation of Aryl lodides
}

\author{
Eric R. Strieter, Donna G. Blackmond, and Stephen L. Buchwald* \\ Department of Chemistry, Massachusetts Institute of Technology, Cambridge, Massachusetts 02139 \\ and the Department of Chemistry, Imperial College, London SW7 2AZ, U.K.
}

\section{Supporting Information}

General Information $\quad$ S-2

Experimental Section $\quad$ S-3

Experimental Details for Kinetic Studies Involving Reaction Calorimetry $\quad$ S-4

Figure S1. Correlation between heat flow conversion and GC conversion $\quad$ S-6

Reaction Kinetics

Figure S2. Determination of Kinetic Order in Catalyst $\quad$ S-7

Figure S3. Determination of Kinetic Order in $\mathrm{K}_{3} \mathrm{PO}_{4} \quad$ S-8

Figure S4. Determination of Kinetic Order in Aryl Iodide S-9

Derivation of Equation $2 \quad \mathrm{~S}-10$

${ }^{1} \mathrm{H}$ NMR experiments with $5 \quad$ S-11

Figure S5. Representative Kinetics for the Arylation of $5 \quad$ S-12 in the Presence of $\mathbf{3}$ 


\section{General Information}

Reagents: Copper(I) iodide (fine grey powder) was purchased from Strem Chemicals and stored in an amber vial in a dessicator. Racemic trans-1,2-cyclohexanediamine was purchased from Aldrich. The quality of the inorganic base $\mathrm{K}_{3} \mathrm{PO}_{4}$ is quite important. Reproducible results were obtained with $\mathrm{K}_{3} \mathrm{PO}_{4}$ available from Fluka (catalog number 04347, Riedel-de Haën product; free-flowing, fine granule of uniform size) and dried under high vacuum at $150{ }^{\circ} \mathrm{C}$ for 3 days. The dried $\mathrm{K}_{3} \mathrm{PO}_{4}$ was then stored in a nitrogen-filled glovebox. It is important to note that the particle size of $\mathrm{K}_{3} \mathrm{PO}_{4}$ is critical for reproducible kinetics, i.e., using $\mathrm{K}_{3} \mathrm{PO}_{4}$ purchased from Alfa Aesar or Aldrich (both of variable size ranging from fine powder to large chunks) led to irreproducible kinetics and in some instances complete inhibition of the reaction. 2-Pyrrolidinone (2) was purchased from Aldrich and distilled over $4 \AA$ molecular sieves prior to its use. 3,5-dimethyliodobenzene (1) was also purchased from Aldrich and distilled from $\mathrm{CaH}_{2}$ prior to its use. Toluene was purchased from J.T. Baker in CYCLE-TAINER solvent delivery kegs, was vigorously purged with $\operatorname{argon}$ for $2 \mathrm{~h}$, and then purified by passing through two packed columns of neutral alumina under argon pressure. All reagents with the exception of copper(I) iodide were stored and weighed out inside a nitrogen-filled glovebox.

Analytical methods: ${ }^{1} \mathrm{H}$ NMR and ${ }^{13} \mathrm{C}$ NMR were recorded on either a Varian $500 \mathrm{MHz}$ Fourier transform NMR spectrometer with chemical shifts reported with respect to residual deuterated solvent peaks. 


\section{Experimental Section}

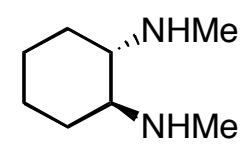

Preparation of racemic trans- $N, N^{\prime}$-dimethyl-1,2-cyclohexanediamine (3). A procedure reported by

Betschart et al. was adapted with small modifications. ${ }^{1}$ A solution of racemic trans-1,2cyclohexanediamine $(10.0 \mathrm{~mL}, 0.041 \mathrm{mmol})$ in ethyl formate $(50 \mathrm{~mL}, 0.25 \mathrm{mmol})$ was heated at $50{ }^{\circ} \mathrm{C}$ for $8 \mathrm{~h}$. The resulting thick, white suspension was allowed to reach room temperature and filtered. After the filter cake was washed with ethyl acetate $(80 \mathrm{~mL})$, the solid was dried under vacuum to give $5.38 \mathrm{~g}$ (77\% yield) of trans- $N, N$ '-diformyl-1,2-cyclohexanediamine.

A $500 \mathrm{~mL}$ three-necked-round bottom flask equipped with a large Teflon-coated stirbar reflux condenser and gas inlet was charged with $\mathrm{LiAlH}_{4}(8.8 \mathrm{~g}, 0.23$ moles $)$ and purged with argon. THF (250 mL) was added and the resulting suspension cooled to $0{ }^{\circ} \mathrm{C}$. $\operatorname{trans}-N, N^{\prime}$-diformyl-1,2-cyclohexanediamine (11.6 g, 68 moles) was added as a solid over $0.5 \mathrm{~h}$ (CAUTION: hydrogen gas evolution!). The cooling bath was replaced with an oil bath and the slightly cloudy, colorless solution was heated at $65^{\circ} \mathrm{C}$ for $24 \mathrm{~h}$ under a slow stream of argon. The resulting white suspension was cooled to $0{ }^{\circ} \mathrm{C}$ and then carefully quenched by dropwise addition of water $(10 \mathrm{~mL}$; CAUTION: violently exothermic reaction, evolution of hydrogen gas!) followed by a $20 \%$ aq $\mathrm{NaOH}$ solution $(75 \mathrm{~mL})$. The resulting gelatinous suspension was stirred at room temperature for $1 \mathrm{~h}$, mixed with Celite $(35 \mathrm{~g})$, and filtered eluting with THF (500 mL). The colorless filtrate was concentrated using a rotary evaporation. The residue was dissolved in a solution of $10 \%$ aq $\mathrm{HCl}(100 \mathrm{~mL})$ in water $(100 \mathrm{~mL})$ and the resulting solution was extracted with dichloromethane $(3 \mathrm{x} \sim 200 \mathrm{~mL})$. The aqueous phase was basified with $20 \%$ aq $\mathrm{NaOH}(100 \mathrm{~mL})$ and extracted with dichloromethane $(3 \mathrm{x} \sim 200 \mathrm{~mL})$. The organic phases from the last extraction were combined, dried $\left(\mathrm{K}_{2} \mathrm{CO}_{3}\right)$, and concentrated using a rotary evaporation. The residue was transferred into a $25 \mathrm{~mL}$ flask and distilled under vacuum to give $8.0 \mathrm{~g}$ (93\% yield) of trans- $N, N^{\prime}$-dimethyl-1,2cyclohexanediamine as a colorless liquid.

\footnotetext{
${ }^{1}$ Betschart, C.; Schmidt, B.; Seebach, D. Helv. Chim. Acta 1988, 71, 1999.
} 


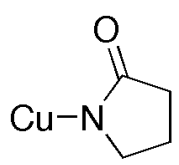

5

Preparation of Copper(I)-pyrrolidinoate (5). 2-pyrrolidinone (2) (260 mg, $3.05 \mathrm{mmol}$ ) was added at ambient temperature to $10 \mathrm{~mL}$ of toluene containing mesitylcopper ${ }^{2}(500 \mathrm{mg}, 2.75 \mathrm{mmol})$ inside a nitrogen-filled glovebox. The colorless mixture was allowed to stir for 15 minutes at ambient temperature prior to the removal of volatiles under high vacuum. The resulting white solid was washed with hexanes $(25 \mathrm{~mL})$ and dried under vacuum affording $350 \mathrm{mg}(86 \%)$ of an air-sensitive white solid. ${ }^{1} \mathrm{H}$ NMR $\left(\mathrm{C}_{6} \mathrm{D}_{6}, 500 \mathrm{MHz}\right) \delta 1.58$ (br m, 2H), 2.04 (br m, 2H), 3.20 (br m, 2H). ${ }^{13} \mathrm{C} \mathrm{NMR}\left(\mathrm{C}_{6} \mathrm{D}_{6}, 125\right.$ $\mathrm{MHz}) \delta 25.09,31.37,52.83,185.12$.

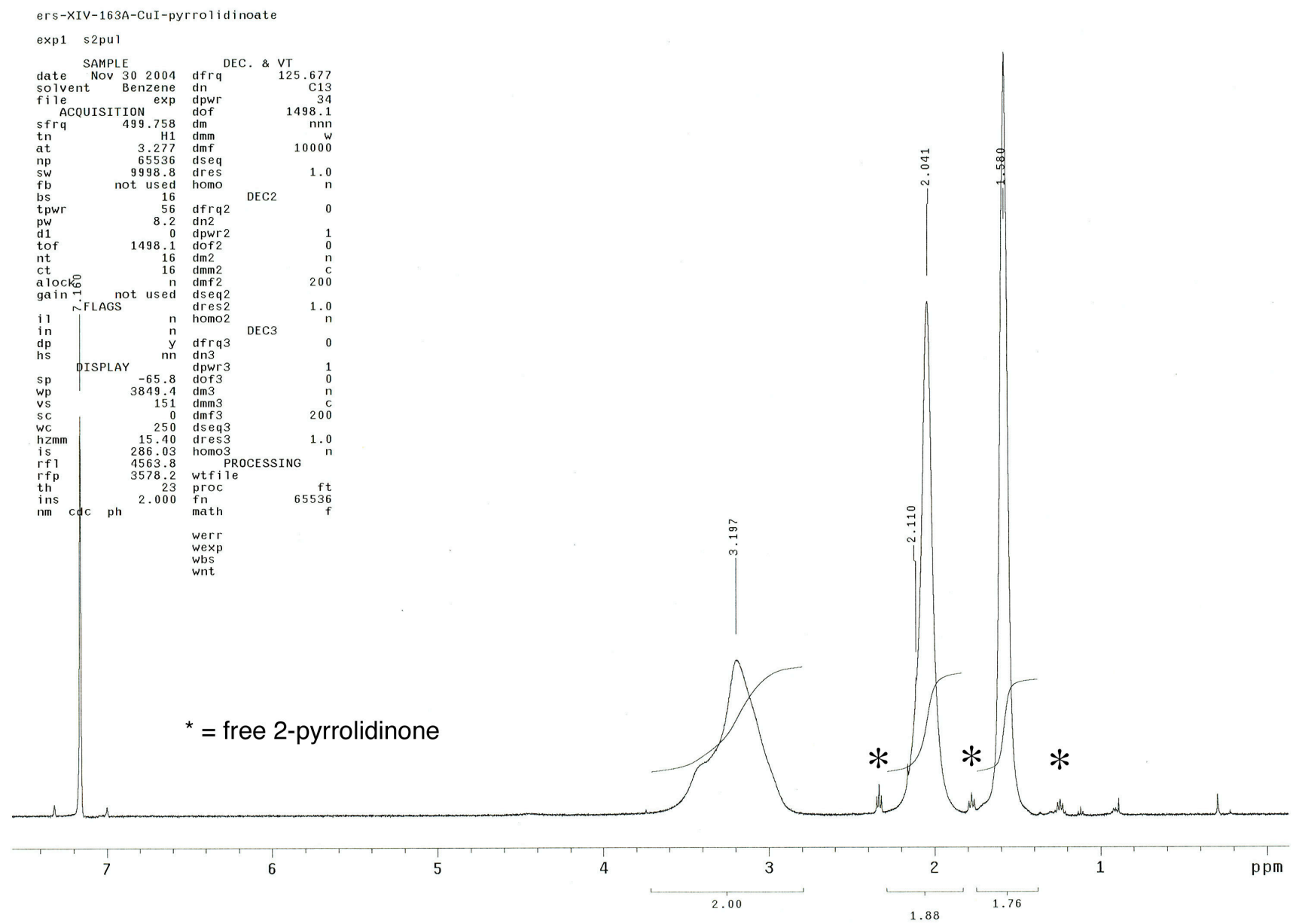

${ }^{2}$ Meyer, E. M.; Gambarotta, S.; Floriani, C.; Chiesi-Villa, A.; Guastini, C. Organometallics 1989, 8, 1067. 


\section{Experimental Procedure for Kinetic Studies Using Reaction Calorimetry}

Reaction procedure. Reactions were performed in an Omnical SuperCRC reaction calorimeter. The instrument contains an internal magnetic stirrer and a differential scanning calorimeter (DSC), which compares the heat released or consumed in a sample vessel to an empty reference vessel. The reaction vessels were $16 \mathrm{~mL}$ borosilicate screw-thread vials fit with opentop black phenolic screw caps and white PTFE septa (KimbleBrand) charged with Teflon stir bars. Sample volumes did not exceed $2.5 \mathrm{~mL}$. In a typical calorimetry experiment, a solution of copper iodide and diamine in toluene was added to a reaction vessel containing $\mathrm{K}_{3} \mathrm{PO}_{4}$, which was placed in the calorimeter and stirred for one hour, allowing the contents of the vessel to reach thermal equilibrium. Simultaneously, a syringe containing 3,5dimethyliodobenzene and 2-pyrrolidinone was placed in the sample injection port of the calorimeter and was allowed to thermally equilibrate. The reaction was initiated by injecting the mixture of aryl iodide and amide into the stirred catalyst- $\mathrm{K}_{3} \mathrm{PO}_{4}$ solution. The temperature of the DSC was held constant at 363 $\mathrm{K}$ using the internal temperature controller in the calorimeter, ensuring that the reaction would proceed under isothermal conditions. A raw data curve was produced by measuring the heat flow from the sample vessel every fifteen seconds during the reaction. Due to the delay between the instantaneous moment heat is evolved from the reaction vessel and the time the thermophile sensor detects the heat flow, the raw data curve must be calibrated. To accomplish this calibration, a constant amount of current was passed through a resistor in the sample chamber of the calorimeter thereby producing a known quantity of heat. This process results in a response curve, which is then transformed into a square wave allowing for the response time of the instrument to be calculated using the WinCRC software. Application of the response time to the raw data results in a "tau corrected data curve." The tau corrected data curve is a plot of heat flow $\left(\mathrm{mJ} \mathrm{s}^{-1}\right)$ versus time. The reaction rate, which is directly proportional to the heat flow (eq 1), fraction conversion (eq 2), and instantaneous concentrations of reactants/products can all be calculated from this tau corrected data curve. Conversion measured by GC analysis was compared to conversion measured by heat flow (Figure S1). Agreement between the two methods validates the use of reaction calorimetry to follow the copper-catalyzed amidation of aryl iodides.

$$
q=\Delta H_{r x n} \cdot V \cdot r
$$

$q$ is the reaction heat flow, $\Delta \mathrm{H}_{\mathrm{rxn}}$ is the heat of reaction, $\mathrm{V}$ is the reaction volume, and $r$ is the reaction rate 


$$
\text { fractional conversion }=\frac{\int_{0}^{t} q \cdot d t}{\int_{0}^{t_{f}} q \cdot d t}
$$

The numerator represents the area under the heat flow to any time point $t$ and the denominator represents the total area under the heat flow curve.

Figure S1. Comparison of conversion measured by heat flow to the conversion measured by GC analysis.

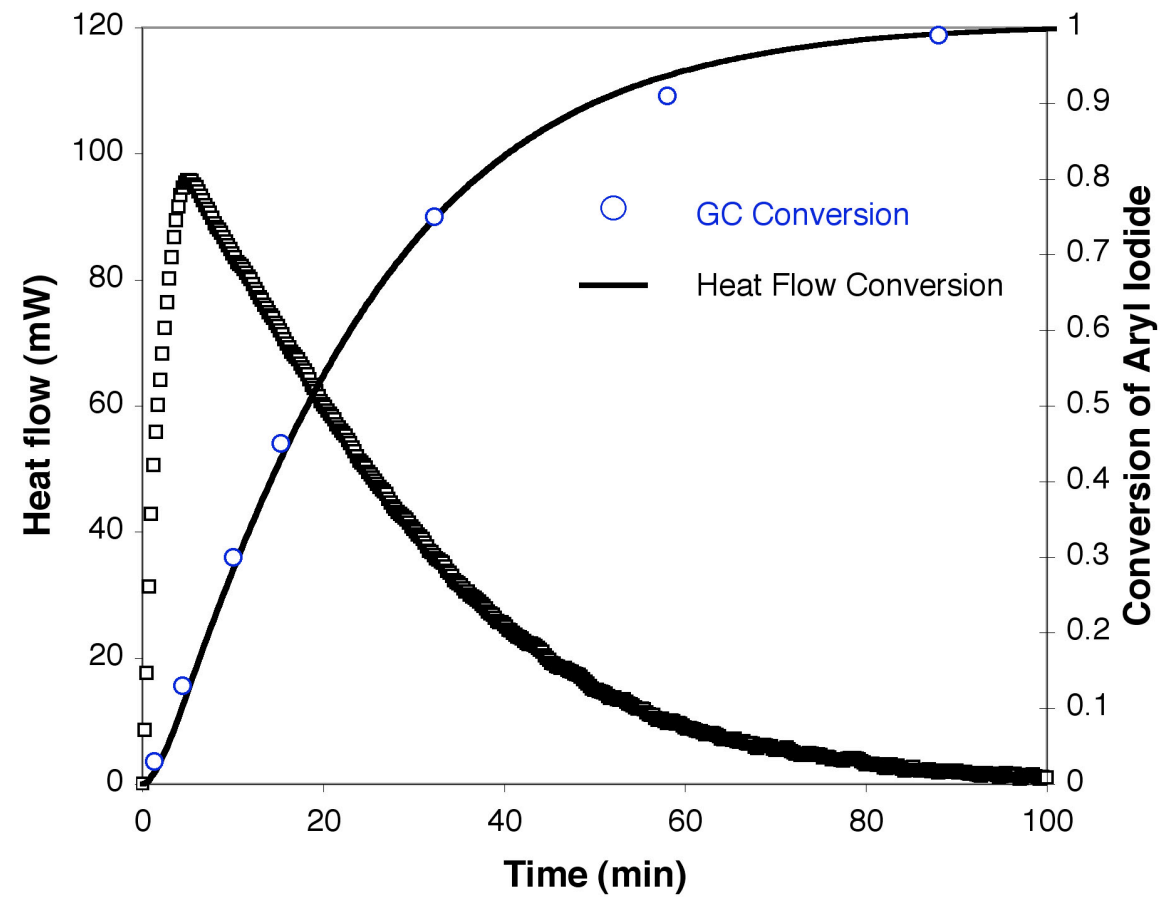

Reaction Conditions: [3,5-dimethyliodobenzene $]_{0}=0.4 \mathrm{M},[2 \text {-pyrrolidinone }]_{0}=0.8 \mathrm{M},\left[\mathrm{K}_{3} \mathrm{PO}_{4}\right]_{0}=1.0$ $\mathrm{M},[\mathrm{CuI}]=0.02 \mathrm{M},\left[\right.$ trans $-N, N^{\prime}$-dimethyl-1,2-cyclohexanediamine $]=0.04 \mathrm{M}$ in $2.0 \mathrm{~mL}$ of Toluene at $363 \mathrm{~K}$. 


\section{$\underline{\text { Reaction Kinetics }}$}

Figure S2. Determination of Kinetic Order in Catalyst Concentration.
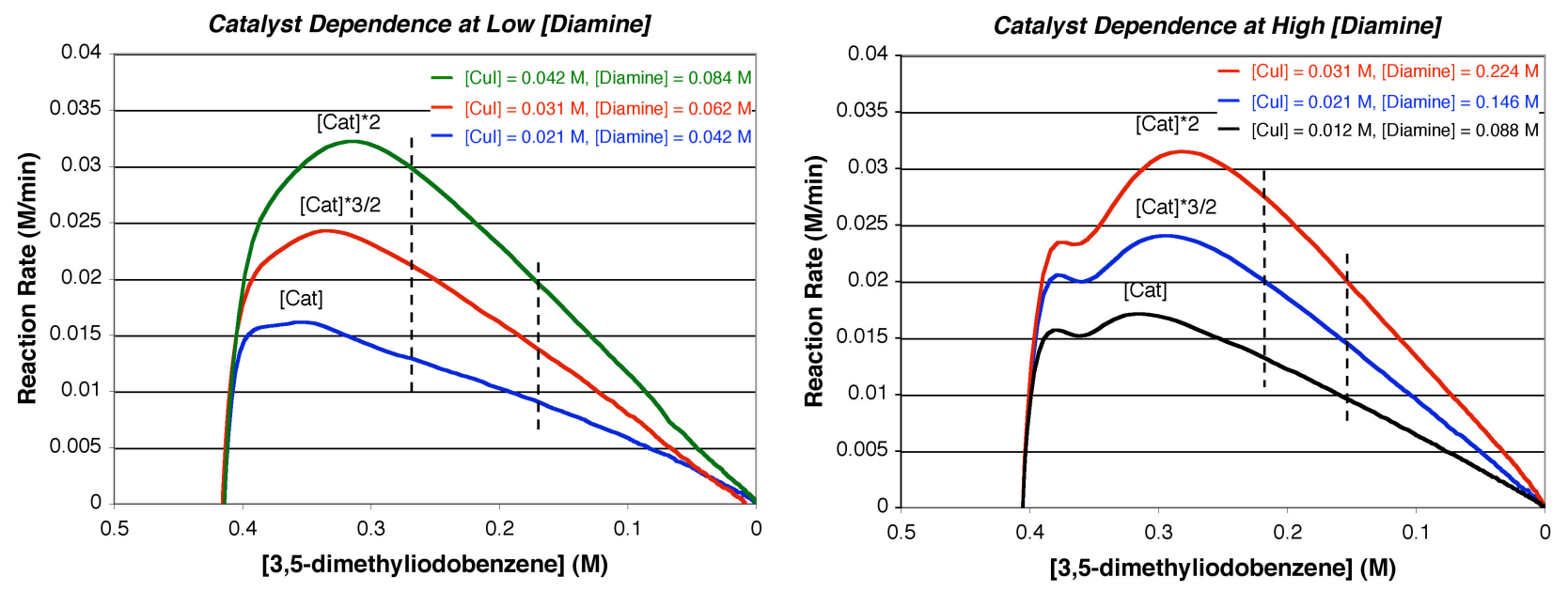

For the lowest catalyst loading at high [diamine] (black curve), $\mathrm{CuI}(6 \mathrm{mg}, 0.032 \mathrm{mmol}$ ) was added to a $16 \mathrm{~mL}$ calorimetry vial charged with a Teflon stir bar and $\mathrm{K}_{3} \mathrm{PO}_{4}(520 \mathrm{mg}, 2.45 \mathrm{mmol})$ inside a nitrogenfilled glovebox. To this mixture was added $2 \mathrm{~mL}$ of Toluene, dodecane (170 mg, $1.0 \mathrm{mmol})$, and $\mathbf{3}$ (41 $\mathrm{mg}, 0.288 \mathrm{mmol}$ ) via syringe. The vial was capped with a PTFE septum and opentop screw cap and brought outside of the glovebox and placed in the calorimeter and allowed to thermally equilibrate at $363 \mathrm{~K}$ for $1 \mathrm{~h}$. A syringe containing 3,5-dimethyliodobenzene (1) (241 mg, $1.04 \mathrm{mmol})$ and 2pyrrolidinone (2) (170 mg, $2.0 \mathrm{mmol})$ was simultaneously placed in the injector port; after one hour, it was injected into the reaction mixture. The same procedure was carried out for all other catalyst loadings. These runs show that the reaction is first order in catalyst throughout the entire course of the reaction. The reaction rate linearly increases with the catalyst concentration while maintaing a constant $\mathrm{Cu}: 3$ ratio. Vertical lines indicate visually convenient conversions to see that this is the case. 


\section{$\underline{\text { Reaction Kinetics }}$}

Figure S3. Determination of Kinetic Order in $\mathrm{K}_{3} \mathrm{PO}_{4}$
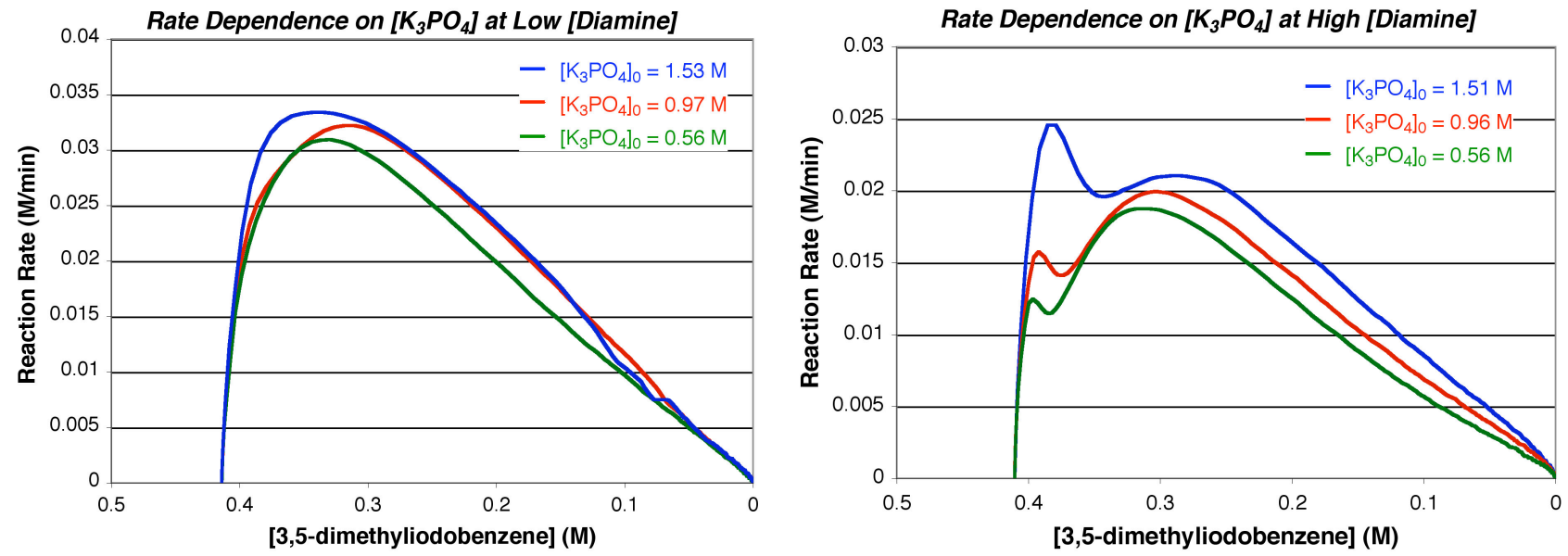

For each of the experiments at low [Diamine], CuI (20 mg, $0.105 \mathrm{mmol})$ was added to a $16 \mathrm{~mL}$ calorimetry vial charged with a Teflon stir bar and a given amount of $\mathrm{K}_{3} \mathrm{PO}_{4}$ inside a nitrogen-filled glovebox. To this mixture was added $2 \mathrm{~mL}$ of Toluene, dodecane (170 mg, $1.0 \mathrm{mmol})$, and $\mathbf{3}$ (30 $\mathrm{mg}$, $0.21 \mathrm{mmol}$ ) via syringe. The vial was capped with a PTFE septum and opentop screw cap and brought outside of the glovebox and placed in the calorimeter and allowed to thermally equilibrate at $363 \mathrm{~K}$ for 1 h. A syringe containing 3,5-dimethyliodobenzene (1) (241 mg, $1.04 \mathrm{mmol}$ ) and 2-pyrrolidinone (2) (170 $\mathrm{mg}, 2.0 \mathrm{mmol}$ ) was simultaneously placed in the injector port; after one hour, it was injected into the reaction mixture. At high [Diamine] the same procedure was performed, however, different amounts of $\mathrm{CuI}(10 \mathrm{mg}, 0.052 \mathrm{mmol})$ and $\mathbf{3}(101 \mathrm{mg}, 0.71 \mathrm{mmol})$ were used. Once a steady-state is obtained (specifically for the experiments with high [Diamine], these runs show that the reaction rate does not change significantly over ca. 3-fold change in $\mathrm{K}_{3} \mathrm{PO}_{4}$ concentration, thus, the reaction rate exhibits nearly zero-order kinetics in $\left[\mathrm{K}_{3} \mathrm{PO}_{4}\right]$. It is also important to note that the $\Delta \mathrm{H}_{\mathrm{rxn}}(163.13 \pm 2.45 \mathrm{~kJ} / \mathrm{mol})$ for all of these experiments does not change significantly. This may not be the case if increasing the amount of $\mathrm{K}_{3} \mathrm{PO}_{4}$ increases the solubility of this inorganic base. 


\section{$\underline{\text { Reaction Kinetics }}$}

Figure S4. Determination of Kinetic Order in Aryl Iodide
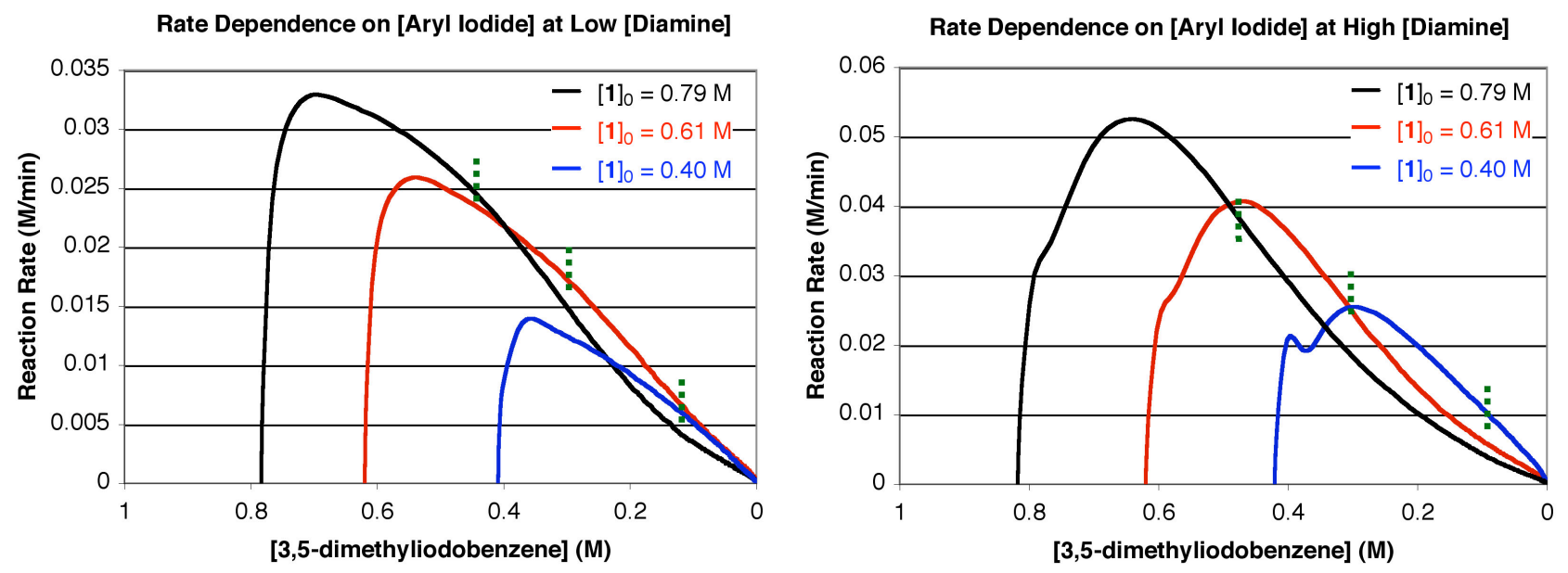

For each of the experiments at low [Diamine], CuI (10 mg, $0.052 \mathrm{mmol})$ was added to a $16 \mathrm{~mL}$ calorimetry vial charged with a Teflon stir bar and $\mathrm{K}_{3} \mathrm{PO}_{4}(520 \mathrm{mg}, 2.45 \mathrm{mmol})$ inside a nitrogen-filled glovebox. To this mixture was added $2 \mathrm{~mL}$ of Toluene, dodecane (170 mg, $1.0 \mathrm{mmol})$, and $\mathbf{3}$ (15 mg, $0.105 \mathrm{mmol}$ ) via syringe. The vial was capped with a PTFE septum and opentop screw cap and brought outside of the glovebox and placed in the calorimeter and allowed to thermally equilibarte at $363 \mathrm{~K}$ for 1 h. A syringe containing a given amount of 3,5-dimethyliodobenzene (1) and 2-pyrrolidinone (2) (170 $\mathrm{mg}, 2.0 \mathrm{mmol}$ ) was simultaneously placed in the injector port; after one hour, it was injected into the reaction mixture. The same procedure was carried out for the experiments at high [Diamine], however, $101 \mathrm{mg}(0.71 \mathrm{mmol})$ of $\mathbf{3}$ was used instead. Although the first order dependence on [1] is not apparent from these complex rate profiles due to the changing rate dependence on [2] over the course of each reaction, examining the reaction rates at identical concentrations of $\mathbf{2}$ lends greater insight into the rate dependence on 1. From the vertical lines in each of these plots, which indicate where identical concentrations of $\mathbf{2}$ exist, the first order dependence on [1] becomes visible. For example, when [2] is equal to $0.5 \mathrm{M}$ at low [Diamine] the rate is $0.024,0.017$, and $0.006 \mathrm{M} / \mathrm{min}$ when [1] is $0.43,0.32$, and $0.12 \mathrm{M}$ respectively. In addition, when [2] is equal to $0.5 \mathrm{M}$ at high [Diamine] the rate is $0.04,0.028$, and $0.01 \mathrm{M} / \mathrm{min}$ when $[\mathbf{1}]$ is $0.48,0.33$, and $0.9 \mathrm{M}$ respectively. 


\section{Derivation of Equation 2}

Major Species at Low

[Diamine]
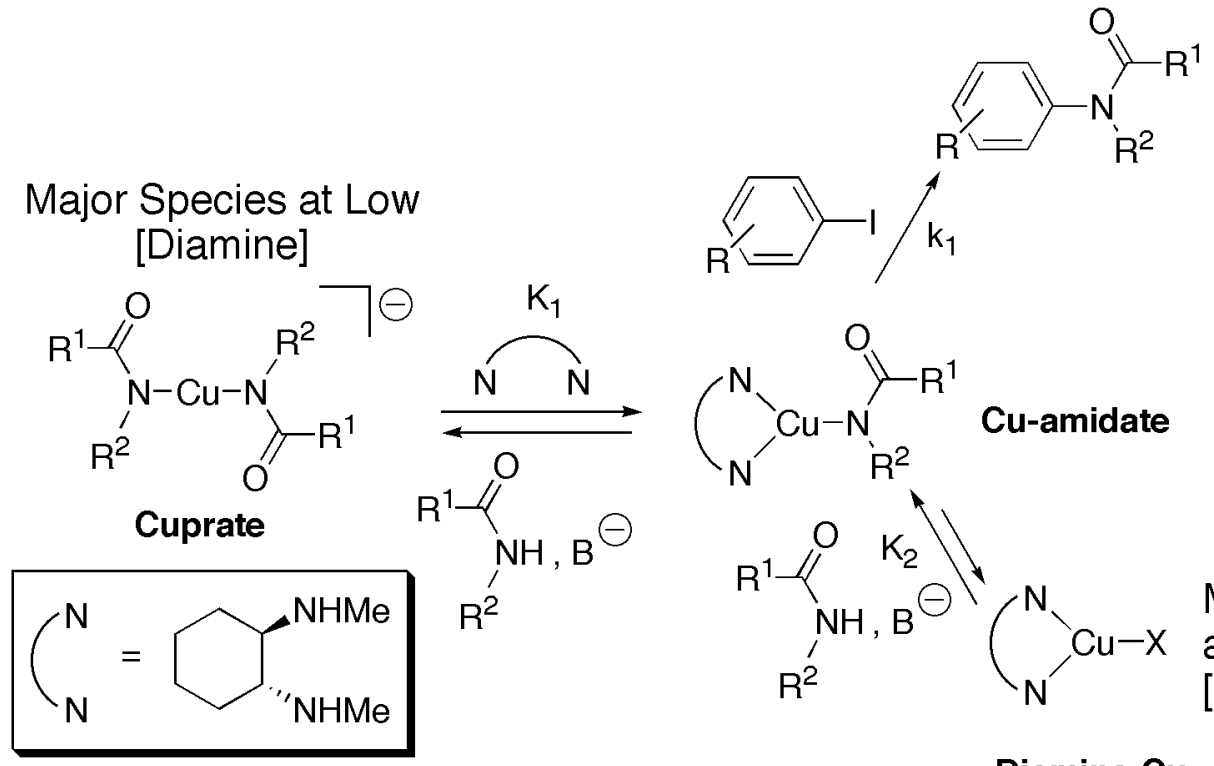<smiles>[R]C(=O)N[14C]1NCCN1</smiles>

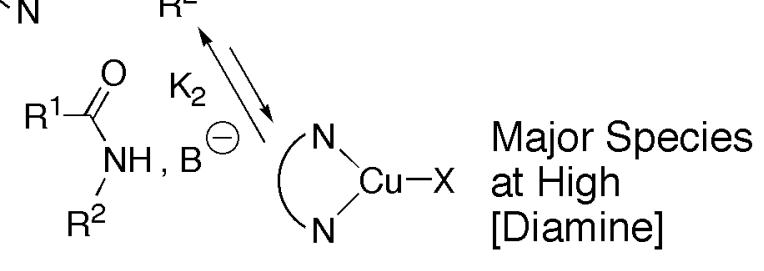

\section{Diamine-Cu}

$$
\begin{aligned}
& \text { rate }=\mathrm{k}_{1}[\mathrm{Cu} \text {-amidate }][\mathrm{Arl}] \\
& {[\mathrm{Cu}]_{\text {total }}=[\text { Cuprate }]+[\text { Diamine-Cu }]+[\mathrm{Cu} \text {-amidate }]} \\
& \mathrm{K}_{1}=\frac{[\text { Cu-amidate }][\text { Amide }]}{[\text { Cuprate }][\text { Diamine }]} \quad \mathrm{K}_{2}=\frac{[\text { Cu-amidate }]}{[\text { Diamine-Cu }][\text { Amide }]} \\
& {[\text { Cuprate }]=\frac{[\text { Cu-amidate }][\text { Amide }]}{\mathrm{K}_{1}[\text { Diamine }]} \quad[\text { Diamine-Cu }]=\frac{[\text { Cu-amidate }]}{\mathrm{K}_{2}[\text { Amide }]}} \\
& {[\mathrm{Cu}]_{\mathrm{t}}=\frac{[\text { Cu-amidate }][\text { Amide }]}{\mathrm{K}_{1}[\text { Diamine }]}+\frac{[\mathrm{Cu} \text {-amidate }]}{\mathrm{K}_{2}[\text { Amide }]}+[\text { Cu-amidate }]} \\
& {[\mathrm{Cu}]_{\mathrm{t}}=[\text { Cu-amidate }]\left(\frac{\mathrm{K}_{2}[\text { Amide }]^{2}+\mathrm{K}_{1}[\text { Diamine }]+\mathrm{K}_{1} \mathrm{~K}_{2}[\text { Amide }][\text { Diamine }]}{\mathrm{K}_{1} \mathrm{~K}_{2}[\text { Diamine }][\text { Amide }]}\right)} \\
& \text { rate }=\frac{\mathrm{k}_{1} \mathrm{~K}_{1} \mathrm{~K}_{2}[\mathrm{Cu}]_{\mathrm{t}}[\text { Arl }][\text { Diamine }][\text { Amide }]}{\mathrm{K}_{2}[\text { Amide }]^{2}+\mathrm{K}_{1}[\text { Diamine }]+\mathrm{K}_{1} \mathrm{~K}_{2}[\text { Amide }][\text { Diamine }]}
\end{aligned}
$$




\section{$\underline{{ }^{1} \mathrm{H}}$ NMR experiments with $\mathbf{5}$}

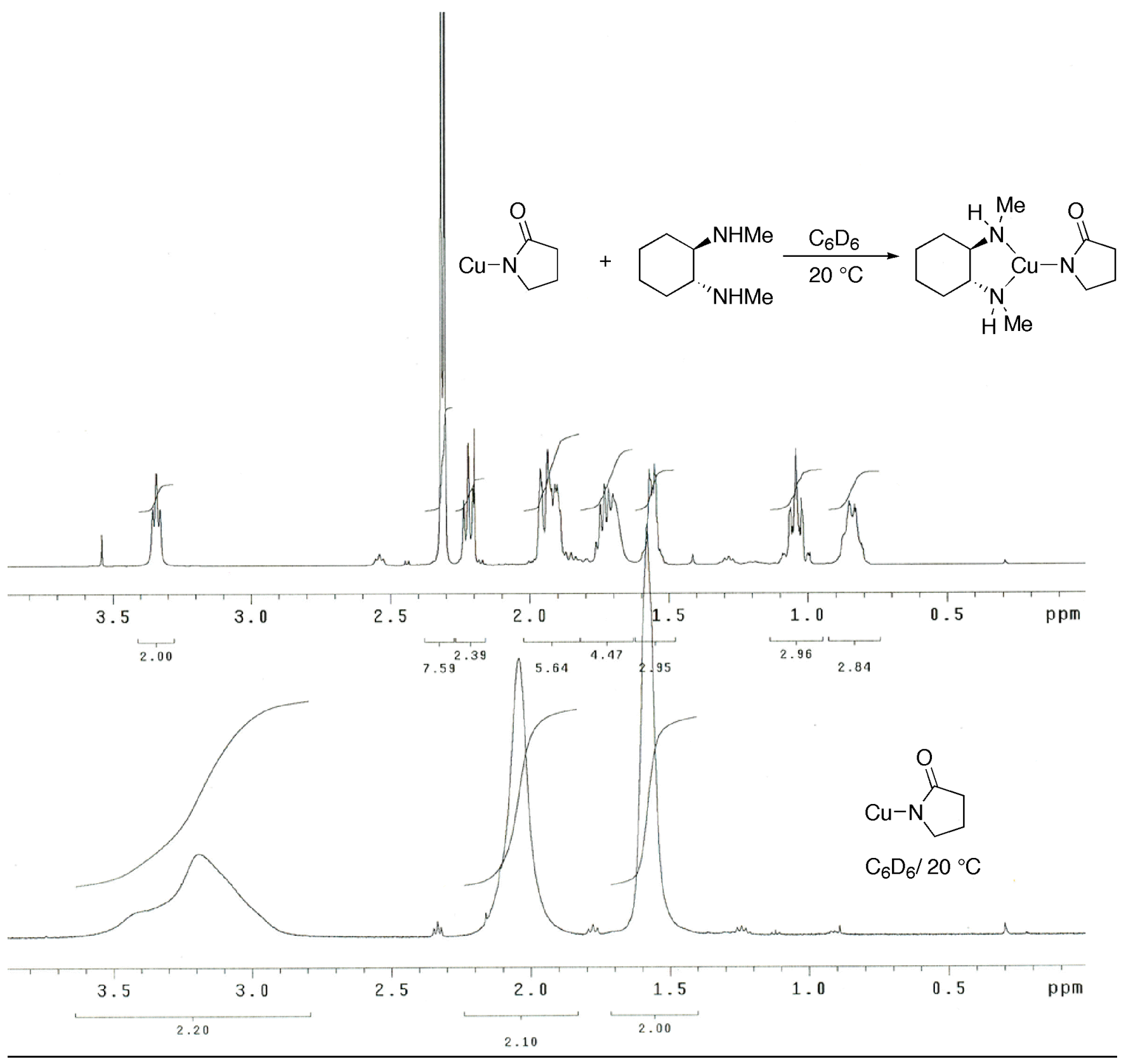




\section{${ }^{1} \mathrm{H}$ NMR experiments with $\mathbf{5}$}

An NMR tube was charged with $1 \mathrm{~mL}$ of a solution containing 5 (76 mg, $0.51 \mathrm{mmol})$ and 3 (76 mg, 0.52 $\mathrm{mmol}$ ) in $\mathrm{d}_{8}$-toluene ( $5 \mathrm{~mL}$ total volume) inside a nitrogen-filled glovebox. The tube was capped with a PTFE septum and opentop screw cap and brought outside of the glovebox and placed in a $500 \mathrm{MHz}$ NMR spectrometer cooled to $273 \mathrm{~K}$. Upon addition of $\mathbf{1}$ (120 mg, $0.52 \mathrm{mmol})$ to the NMR tube, data was collected every minute.

Figure S5. Representative Kinetics for the Arylation of $\mathbf{5}$ in the Presence of $\mathbf{3}$.

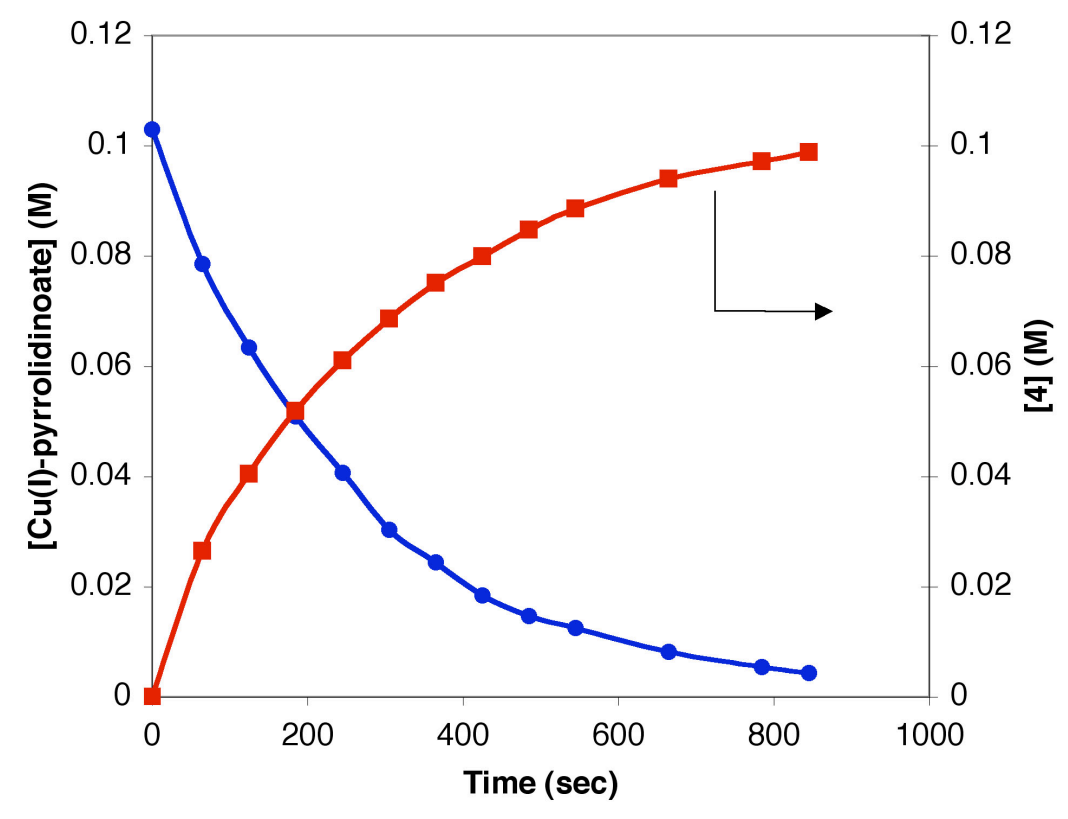

